\title{
Beautiful Protector, a 3D Printed Neckpiece
}

Jennise Thurston, Dr. Michael Mamp

\section{Central Michigan University, USA}

Keywords: 3d printing, protection, art-wear, beadwork, feathering

Beautiful Protector was designed to reflect internal and emotional concepts of protection in an outward form of adornment. It is an artistic statement of how the walls we choose to build do protect us, but can also leave us alone and unable to interact fully with the outside world.

Throughout history, clothing has been used as a way to protect oneself from the elements, and as reflection of modesty. In the sixteenth and seventeenth centuries the ruff emerged as symbolic of status and as a decorative and yet physical means (whether consciously or subconsciously) of distancing oneself from others. (Tortora \& Marcketti, 2015). The native Maasai people of Africa use adorned collars and other types of beadwork as a way of distinguishing themselves. According to Blauer (2000), "people within that culture can read a woman's exact status--her age-set, marital status, even whether she has given birth to a son--by observing her beaded jewelry" (p. 208). This idea of being able to interpret someone's life by outward adornment

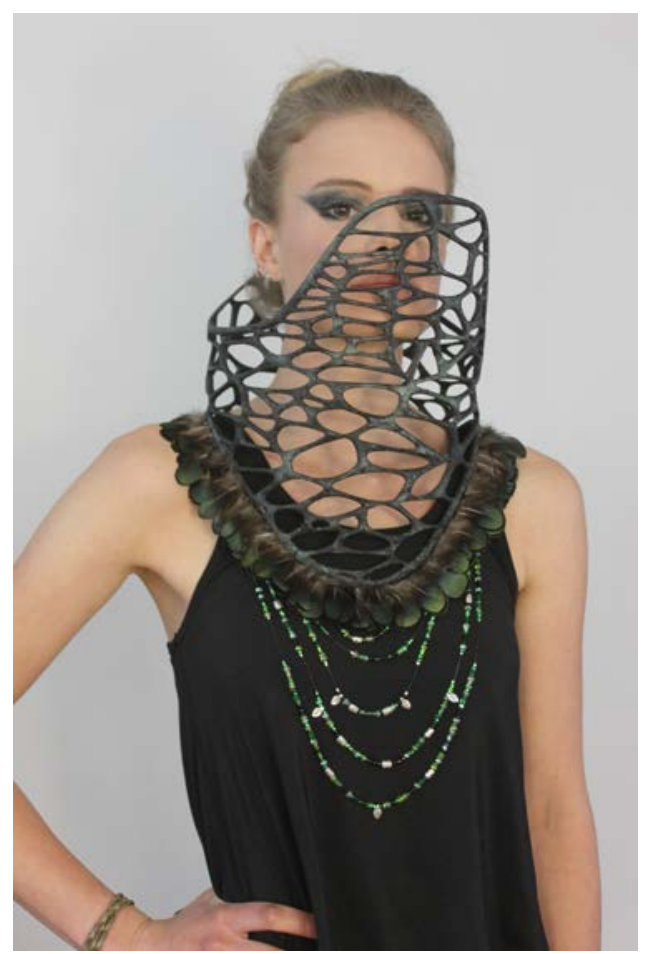

Figure 1: Beautiful Protector, front view impacted the design of the beaded strands that hang down from the neckpiece. Along with these examples, Hussein Chalayan's Spring 2007 fashion show inspired some of the aesthetic choices employed in the design of this piece. His collection included garments that utilized material and silhouette to provide multiple wearing options, which protected the wearer from a variety of external environs. More recently, designers such as Iris Van Herpen and Francis Bitonti have become synonymous with $3 \mathrm{~d}$ printed fashion and their works were also influential in conceptualizing this neckpiece.

To create this piece, the $3 \mathrm{D}$ printed component was developed via multiple prototypes before the desired look was achieved. Measurements taken from a dress form aided the creation of a flat pattern in illustrator that was then exported into Tinkercad, a $3 \mathrm{~d}$ modeling software. 
Once in Tinkercad, the depth of the model was created and the voronoi cells were applied and cut away from the object. After this treatment, the model was brought into Maya, another $3 \mathrm{~d}$ modeling software, and a bend deformer was applied to make it cylindrical. Multiple prototypes were printed and the design was adjusted to fit flush with the body. Eventually, the final design was printed on a Makerbot Z18 3D printer using PLA filament.

Once printed, the design was sanded to achieve a smooth look. The entire surface was then hand painted black with accents of iridescent blue and green to provide highlights and contrast. Once the main structure of the neckpiece was completed, feathers were attached and decorative strands were constructed using various beads and charms and then attached to the center front and back. The outcome is a neckpiece achieved via advanced technology combined with traditional hand decorative applications.

The significance of this work is related in part to the continued emergence of $3 \mathrm{D}$ printing in fashion. As the software, machinery and materials for creating $3 \mathrm{D}$ printed objects becomes more accessible, it will be important to

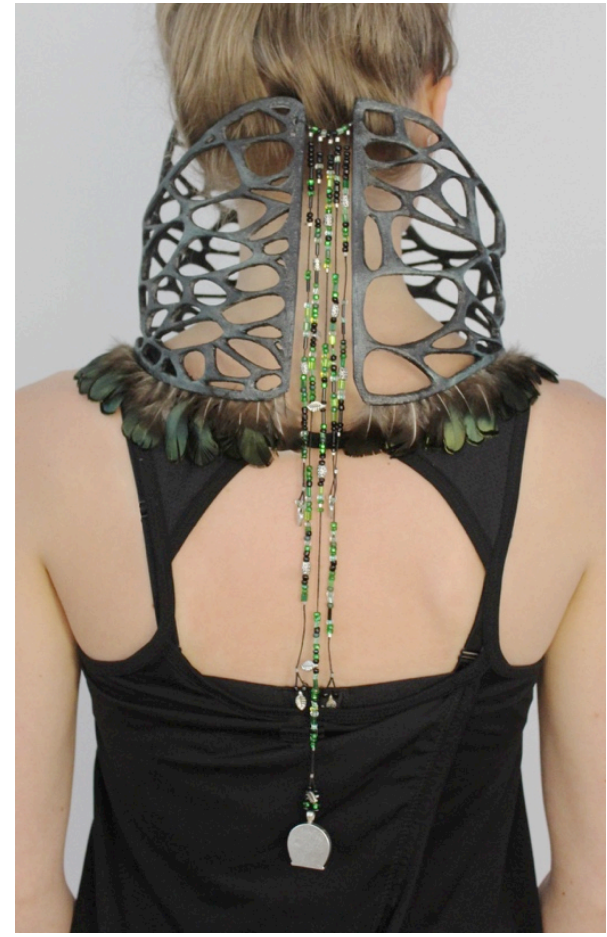

Figure 2: Beautiful Protector, back view further develop our knowledge and understanding of how these materials and technology can be used. Utilization of 3D printing, coupled with traditional techniques of embellishment, created a piece that is unique. Overall, these combined processes allowed for a more diverse interpretation of other designers and cultural references.

\section{References}

Bitonti, Francis. (2015). Manifesto. Retrieved from http://www.francisbitonti.com

Blauer, E. (2000). "Messengers of culture: The glory of African beadwork." World and I, 15(2), 208.

Chalayan, Hussein. (2015). About. Retrieved from http://chalayan.com/about/

Tortora, P., \& Marcketti, B. (2015). Survey of Historic Costume (6th ed.). New York, NY:

Fairchild Publications.

Van Herpen, Iris. (2015). About: Iris Van Herpen. Retrieved from

http://www.irisvanherpen.com/about 